\title{
On Selenoketenes. Formation of 1,3,4-Selenadiazoline from Carbon Diselenide and Diazoalkanes
}

\author{
Rolf H. Berg, ${ }^{a}$ Niels Harrit, ${ }^{a}$ Elfin Larsen ${ }^{b}$ and Arne Holm ${ }^{a, \star}$ \\ ${ }^{a}$ Department of General and Organic Chemistry, The H. C. Ørsted Institute, University of Copenhagen, Universitetsparken 5, \\ DK-2100 Copenhagen $\varnothing$, Denmark and ' ${ }^{b}$ Chemistry Department, Risø National Laboratory, DK-4000 Roskilde, Denmark
}

\begin{abstract}
Berg, R. H., Harrit, N., Larsen, E. and Holm, A., 1989. On Selenoketenes. Formation of 1,3,4-Selenadiazoline from Carbon Diselenide and Diazoalkanes. - Acta Chem. Scand. 43: 885-887.

Di-tert-butyldiazomethane and carbon diselenide react in toluene at $80^{\circ} \mathrm{C}$. A compound isolated in ca. $30 \%$ yield from the mixture has been identified as the di-tertbutyl derivative of the hitherto unknown 2-alkylidene-2,5-dihydro-1,3,4-selenadiazoles. Further investigations indicate that the same ring system is formed upon reaction between di-tert-butyldiazomethane and photochemically generated tert-butylselenoketene. Pyrolysis in the vapor phase of the di-tert-butyl derivative gives rise to a mixture consisting of di-tert-butyl selenoketene and di-tert-butyl selenoketone $(1: 2)$ as well as some secondarily formed di-tert-butyl carbene and di-tert-butyl methylenecarbene.
\end{abstract}

Selenoketenes are generally highly reactive molecules which can be isolated only at low temperatures. ${ }^{1}$ This applies to both aliphatic and aromatic selenoketenes although some selenoketenes substituted with an $\alpha$-silicon atom have been isolated at room temperature. ${ }^{2}$ Selenoketenes have mostly been generated by initiating a Wolff-like rearrangement of 1,2,3-selenadiazoles or by [3,3]-sigmatropic rearrangement of allylic ethynyl selenides. ${ }^{3,4}$ We have investigated the reaction between carbon diselenide 1 and di-tertbutyldiazomethane 2 with the intention of obtaining the unknown selenadiazoline 3 which - by elimination of Se and $\mathrm{N}_{2}$ - is a potential selenoketene precursor. ${ }^{5}$ Such an approach, which does not rely on the migration of a group or an atom, could be particularly useful in the preparation of crowded selenoketenes.

When compounds 1 and 2 were mixed in toluene and heated to $80^{\circ} \mathrm{C}$, the yellow colour of 2 disappeared and the evolution of nitrogen and formation of elemental selenium

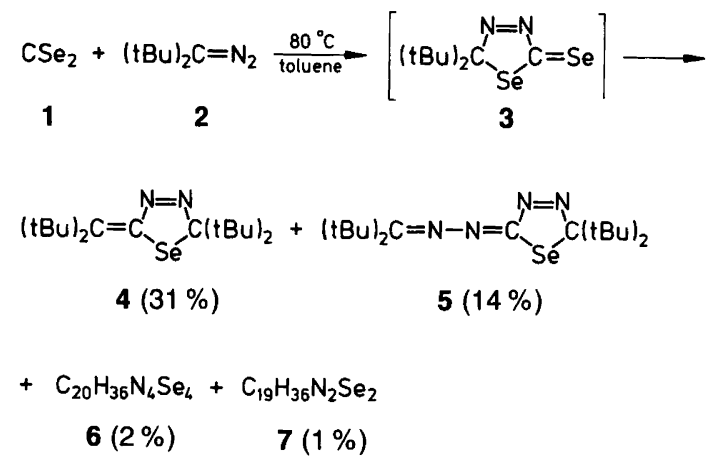

Scheme 1.

\footnotetext{
${ }^{*}$ To whom correspondence should be addressed.
}

were observed. The reaction mixture was worked up using thin layer chromatography to give compounds 4-7 (Scheme 1).

The structure of compound 4 was established on the basis of elemental analysis, ${ }^{1} \mathrm{H},{ }^{13} \mathrm{C}$, and ${ }^{77} \mathrm{Se}$ NMR spectroscopy and MS as well as on supplementary results as discussed below. The tentative identification of compound 5 is based exclusively on the spectroscopic data presented in the Experimental section.

The structure of 4 suggests that this compound may arise from a 1,3-dipolar cycloaddition reaction between the diazo compound present and transient di-tert-butylselenoketene formed as outlined in Scheme 1. Support for the suggested mechanism is obtained from the following experiment. tert-Butylselenoketene was generated by irradiation $^{4}$ of 4-tert-butyl-1,2,3-selenadiazole (8) in the presence of di-tert-butyldiazomethane. Only one product was obtained which, on the basis of elemental analysis and spectral data, was assigned the $Z$ - or $E$-form of 9 (Scheme 2).

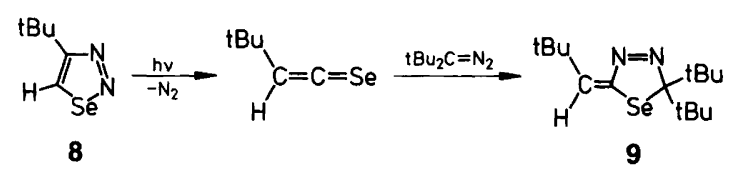

Scheme 2.

Alternative structures 10 and 11 (Scheme 3), which could be formed from unrearranged selenadiazole and di-tertbutylcarbene or from di-tert-butyldiazomethane and a 1,3diradical formed from the selenadiazole by nitrogen extrusion, are ruled out on the basis of the ${ }^{1} \mathrm{H}$ and ${ }^{77} \mathrm{Se}$ NMR off-resonance spectra. These both exhibit a $J_{\mathrm{Se}-\mathrm{H}}$ coupling 
BERG ET AL.

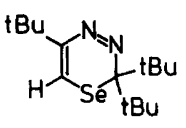

10

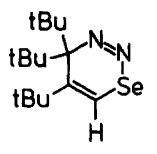

11
Scheme 3.

constant of $10 \mathrm{~Hz}$ which is within the range reported for vicinal ${ }^{3} J_{\mathrm{Se}-\mathrm{H}}$ couplings, but lower than those reported for geminal Se-H $\left({ }^{2} J_{\mathrm{Se}-\mathrm{H}}\right) .{ }^{6}$ The formation of 9 shows that the selenoketene and diazomethane react in the above assumed 1,3-dipolar cycloaddition reaction.

Selenadiazolines 4 and 9 are representatives of a novel class of heterocyclic compound. The corresponding sulfur compounds are known and are obtained by 1,3-dipolar cycloaddition between diazoalkanes and thioketenes. ${ }^{7}$

Compound 4 appeared to be a possible candidate for the thermal formation of di-tert-butylselenoketene. It was thus pyrolyzed at $480^{\circ} \mathrm{C}$ using the Curie point technique and monitoring the reaction with field ionization mass spectrometry (FIMS). Intense peaks are found in the FI-spectrum at $\mathrm{m} / \mathrm{z} 218\left({ }^{80} \mathrm{Se}\right), 206\left({ }^{80} \mathrm{Se}\right)$ and 138 , and a smaller one at 126 which, on the basis of exact mass measurements, are assigned to di-tert-butylselenoketene, di-tert-butyl selenoketone, di-tert-butylmethylenecarbene, and di-tertbutylcarbene, respectively (Scheme 4). When compound 4 was subjected to pyrolysis in the vapor phase in a flow system, a turquoise product was trapped at $-196^{\circ} \mathrm{C}$. On co-condensation with carbon tetrachloride and cautious heating of the mixture to $0^{\circ} \mathrm{C}$, a solution was obtained which was shown by direct MS to contain di-tert-butylselenoketene and di-tert-butyl selenoketone. These are assumed ${ }^{1}$ and known, ${ }^{8}$ respectively, to be blue. No attempts were made to separate the mixture into the individual compounds, which, from the molar intensities, were formed in the approximate ratio 1:2.

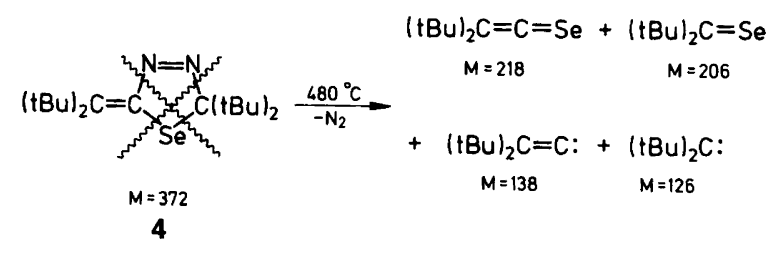

Scheme 4.

\section{Experimental}

${ }^{1} \mathrm{H},{ }^{13} \mathrm{C}$, and ${ }^{77} \mathrm{Se}$ NMR spectra were obtained with a JEOL FX $90 \mathrm{Q}$ instrument $\left(\mathrm{CDCl}_{3} ; \mathrm{SiMe}_{4}\right.$ and $\mathrm{Me}_{2} \mathrm{Se}$ as internal and external standards), UV spectra (cyclohexane) with a Unicam SP $800 \mathrm{~A}$ spectrophotometer, IR spectra $\left(\mathrm{CCl}_{4}\right)$ with a Perkin-Elmer 157 grating spectrometer calibrated against polystyrene (bands noted are either strong or medium in intensity unless denoted as weak (w), and mass spectra with an AEI MS 902 double-focusing spectrometer operating at $70 \mathrm{eV}$ using a direct-insertion probe. Flash vacuum pyrolysis experiments were carried out using a
Varian MAT CH 5D instrument set up as described elsewhere. ${ }^{9}$ Gold-plated filaments with Curie-point $480^{\circ} \mathrm{C}$ were used. A sample of approximately $50 \mu \mathrm{g}$ was placed on the filament. Photochemical reactions were performed using an Osram SP 200 medium-pressure mercury lamp equipped with a monochromator. TLC and PTLC were performed on Merck silica gel $(0.2$ and $2.5 \mathrm{~mm}$, respectively).

Reaction of carbon diselenide with 3-diazo-2,2,4,4-tetramethylpentane. The diazo compound ${ }^{10}(8.36 \mathrm{mmol})$ and an excess of carbon diselenide $(2 \mathrm{ml})$ were dissolved in dry toluene $(15 \mathrm{ml})$ and heated to $80^{\circ} \mathrm{C}$ under nitrogen $(15$ $\mathrm{min})$. Gas was evolved and a red precipitate of elemental selenium formed, which was removed by filtration after the reaction had been cooled to room temperature. A reddish oil remained after evaporation of the solvent in vacuo. TLC analysis [toluene-light petroleum $(1: 6 \mathrm{v} / \mathrm{v})$ ] showed the reaction to be complete and revealed spots at $R_{\mathrm{f}} 0.52,0.46$, 0.28 , and 0.00 . Upon PTLC the first three bands could be eluted using dichloromethane while the band at $R_{\mathrm{f}} 0.00$ was eluted with methanol. The last fraction was obtained as a yellow oil after evaporation of the methanol and was identified as 2,2-di-tert-butyl-5-(di-tert-butylmethylenehydrazono)-5-dihydro-1,3,4-selenadiazole (5) (59 mg, $4 \%$ based upon the diazo compound). Attempts to crystallize this material were unsuccessful. Anal. $\mathrm{C}_{19} \mathrm{H}_{36} \mathrm{~N}_{4} \mathrm{Se}: \mathrm{C}, \mathrm{H}, \mathrm{N} .{ }^{1} \mathrm{H}$ NMR: $\delta 1.34(18 \mathrm{H}, \mathrm{s})$ and $1.22(18 \mathrm{H}, \mathrm{s}) \cdot{ }^{13} \mathrm{C}$ NMR: $\delta$ 174.0 (s), 171.2 (s), 135.8 (s), 43.3 (s), 41.4 (s), 40.5 (s), 31.4 (q), 30.1 (q), and 27.7 (q). ${ }^{77} \mathrm{Se}$ NMR: $\delta 285$ (s). IR: 2920, 2880, 1580, 1470, 1390, 1360, 1220, 1190, 1060, 1030, 980,930 , and $840 \mathrm{~cm}^{-1}$. UV (ع): $380(5300), 269(4600)$, and $225 \mathrm{~nm}(22000)$. MS ( $\left.\mathrm{m} / \mathrm{z}, 90^{\circ} \mathrm{C}\right): 400\left({M^{+}}^{+}\right)(6), 344(7)$, 343 (5), 329 (3), 316 (4), 315 (4), 287 (100), 246 (6), 231 (14), $206(40)$, and $154(49 \%)$.

The major fraction $\left(R_{\mathrm{f}} 0.28\right)$ from PTLC was obtained as an oily solid. Crystallization from methanol afforded yellow crystals of 2,2-di-tert-butyl-5-di-tert-butylmethylene2,5-dihydro-1,3,4-selenadiazole (4) (485 mg, $31 \%$ based upon the diazo compound), m.p. $111.5-112.0^{\circ} \mathrm{C}$. Anal. $\mathrm{C}_{19} \mathrm{H}_{36} \mathrm{~N}_{2} \mathrm{Se}: \mathrm{C}, \mathrm{H}, \mathrm{N} .{ }^{1} \mathrm{H}$ NMR: $\delta 1.60(9 \mathrm{H}, \mathrm{s}), 1.48(9 \mathrm{H}$, $\mathrm{s})$, and $1.18(18 \mathrm{H}, \mathrm{s}) .{ }^{13} \mathrm{C} \mathrm{NMR}: \delta 162.0(\mathrm{~s}), 154.5(\mathrm{~s})$, $128.2(\mathrm{~s}), 43.7(\mathrm{~s}), 43.3(\mathrm{~s}), 38.5(\mathrm{~s}), 35.4(\mathrm{q}), 31.8(\mathrm{q})$, and 30.8 (q). ${ }^{77} \mathrm{Se}$ NMR: $\delta 270$ (s). IR: 2970, 2920, 1600, 1540, $1480,1390,1370,1230,1210,1070,1050,950,910$, and 860 $\mathrm{cm}^{-1}$. UV $(\varepsilon): 380(4700)$, and $224 \mathrm{~nm}(8900)$. MS $(\mathrm{m} / \mathrm{z}$, $\left.100^{\circ} \mathrm{C}\right): 372\left(M^{+}\right)(8), 344(5), 316(8), 315(6), 301(100)$, $285(38), 259(23)$, and $245(38 \%)$.

A third product $\left(R_{\mathrm{f}} 0.46\right)$ could only be separated from the minor component $\left(R_{\mathrm{f}} 0.52\right)$ on an analytical scale. Repeated recrystallizations from methanol gave compound 6 (41 $\mathrm{mg}, 2 \%$ based upon the diazo compound). Anal. $\mathrm{C}_{20} \mathrm{H}_{36} \mathrm{~N}_{4} \mathrm{Se}_{4}: \mathrm{C}, \mathrm{H}, \mathrm{N} .{ }^{1} \mathrm{H}$ NMR: $\delta 1.41(18 \mathrm{H}, \mathrm{s}), 1.35$ $(9 \mathrm{H}, \mathrm{s})$, and $1.33(9 \mathrm{H}, \mathrm{s}) \cdot{ }^{13} \mathrm{C}$ NMR: $\delta 179.4,42.9,42.2$, $40.9,30.6$, and 29.9. IR: 3000, 2950, 2900, 1690, 1580, $1510,1400,1360$, and $1230 \mathrm{~cm}^{-1}$. MS $(\mathrm{m} / z): 572\left(M^{+\cdot}-\mathrm{Se}\right)$, 246,189 , and 160 . With respect to the minor component 
$\left(R_{\mathrm{f}} 0.52\right)$ only a mass spectrum was recorded which indicated $\mathrm{C}_{19} \mathrm{H}_{36} \mathrm{~N}_{2} \mathrm{Se}_{2}(\mathrm{~m} / z$ 452).

Photolysis of 4-tert-butyl-1,2,3-selenadiazole in the presence of 3-diazo-2,2,4,4-tetramethylpentane. The selenadiazole $(0.8 \mathrm{mmol})$ and an excess of the diazo compound $(500 \mathrm{mg})$ in absolute ethanol (1 1 ) were irradiated in the presence of air at $290 \mathrm{~nm}$ for $76 \mathrm{~h}$. TLC [dichloromethane-light petroleum $(3: 4 \mathrm{v} / \mathrm{v})]$ revealed only one new product $\left(\boldsymbol{R}_{\mathrm{f}}\right.$ $0.75)$. After concentration of the reaction mixture in vacuo, unchanged selenadiazole ( $33 \mathrm{mg}$ ) was removed by means of PTLC and the new product was isolated as an oil. Recrystallization of this from methanol afforded yellow crystals of compound 9 ( $48 \mathrm{mg}, 19 \%$ based upon the selenadiazole), m.p. 55.5-56. $5^{\circ} \mathrm{C}$. Anal. $\mathrm{C}_{15} \mathrm{H}_{28} \mathrm{~N}_{2} \mathrm{Se}: \mathrm{C}, \mathrm{H}, \mathrm{N} .{ }^{1} \mathrm{H}$ NMR: $\delta$ $7.16\left(1 \mathrm{H}, \mathrm{S}, J_{\mathrm{Se}-\mathrm{H}} 10 \mathrm{~Hz}\right), 1.23(9 \mathrm{H}, \mathrm{s})$, and $1.19(18 \mathrm{H}, \mathrm{s})$. ${ }^{13} \mathrm{C}$ NMR: $\delta 158.7(1 \mathrm{C}, \mathrm{s}), 146.2(1 \mathrm{CH}, \mathrm{d}), 138.1(1 \mathrm{C}, \mathrm{s})$, $43.7(2 \mathrm{C}, \mathrm{s}), 32.1(1 \mathrm{C}, \mathrm{s}), 30.8\left(6 \mathrm{CH}_{3}, \mathrm{q}\right)$, and 28.8 $\left(3 \mathrm{CH}_{3}, \mathrm{q}\right) .{ }^{77} \mathrm{Se}$ NMR: $\delta 202\left(\mathrm{~s}, J_{\mathrm{Se}-\mathrm{H}} 10 \mathrm{~Hz}\right) . \mathrm{UV}: 360 \mathrm{~nm}$ (EtOH). MS $\left(\mathrm{m} / \mathrm{z}, 100^{\circ} \mathrm{C}\right): 316\left(M^{+\cdot}\right), 301,260,245,204$, and 189.

\section{References}

1. Holm, A., Berg, C., Bjerre, C., Bak, B. and Svanholt, H. J. Chem. Soc., Chem. Commun. (1979) 99; Schultz, R. and Schweig, A. Angew. Chem. 92 (1980) 52; Bock, H., Aygen, S. and Solouki, B. Z. Naturforsch., Teil B 38 (1983) 611; Schultz, R. and Schweig, A. Tetrahedron Lett. 22 (1984) 2337; Z. Naturforsch., Teil B 39 (1984) 1536; Sander, W. W. and Chapman, O. L. J. Org. Chem. 50 (1985) 543.
2. Sukhai, R. S. and Brandsma, L. Recl. Trav. Chim. Pays-Bas 98 (1979) 55; Schaumann, E. and Grably, F.-F. Tetrahedron Lett. (1980) 4251.

3. Meier, H. and Menzel, I. Tetrahedron Lett. (1972) 445; Ghandehari, M. H., Davalian, D., Yalpani, M. and Partovi, M. H. J. Org. Chem. 39 (1974) 3906; Krantz, A. and Laureni, J. J. Am. Chem. Soc. 99 (1977) 4842; Sukhai, R. S., de Jong, R. and Brandsma, L. Synthesis (1977) 888; Bak, B., Nielsen, O. J., Svanholm, H. and Holm, A. Chem. Phys. Lett. 55 (1978) 36; Bock, H., Aygen, S., Rosmus, P. and Solouki, B. Chem. Ber. 113 (1980) 3187; Bak, B., Kristiansen, N., Svanholt, H., Rosenkilde, S. and Holm, A. Chem. Phys. Lett. 78 (1981) 301; Bock, H., Aygen, S. and Solouki, B. Z. Naturforsch., Teil B 38 (1983) 611

4. Harrit, N., Rosenkilde, S., Larsen, B. D. and Holm, A. J. Chem. Soc., Perkin Trans. 1 (1985) 907, 1818; see also Refs. 1 and 2.

5. A closely related 2,5-disubstituted 1,3,4-thiadiazoline undergoes elimination of sulfur and nitrogen in the presence of trimethyl phosphite with formation of a double bond between positions 2 and 5: Bushby, R. J. and Pollard, M. D. J. Chem. Soc., Perkin Trans 1 (1979) 2401.

6. Johannsen, I., Henriksen, L. and Eggert, H. J. Org. Chem. 51 (1986) 1657.

7. Middleton, W. J. J. Org. Chem. 34 (1969) 3201; Schaumann, E., Behr, H. and Lindstaedt, J. Chem. Ber. 116 (1983) 66.

8. Elam, E. U., Rash, F. H., Dougherty, J. T., Goodlett, V. W. and Brannock, K. C. J. Org. Chem. 33 (1968) 2738.

9. Carlsen, L., Egsgaard, H., Schaumann, E., Mrotzek, H. and Klein, W.-R. J. Chem. Soc., Perkin Trans. 2 (1980) 1557.

10. Barton, D. H. R., Guziec, F. S., Jr. and Shahak, I. J. Chem. Soc., Perkin Trans. 1 (1974) 1794.

Received April 3, 1989. 